\title{
Infections in Long-Term Care Facilities
}

These statistics speak for themselves: the population aged 65 to 85 is projected to increase $15 \%$ (from 26 to 30 million) by the year 2000 . But the population aged 85 and over will nearly double from 2.6 million to about 5 million by the year 2000 . Currently, about $20 \%$ of the very elderly individuals reside in nursing homes. There are now about 1.3 million beds in 18,000 nursing homes in the United States. If the above projections of the elderly population hold true, then we would need approximately one-half million nursing home beds in the next 15 years. ${ }^{1}$

Although the field of hospital infection control is well established, only in the last several years has attention been turned to nosocomial infections in nursing homes. The article by Price et al in this issue of Infection Control certainly adds to our knowledge of the problem. ${ }^{2}$ Noting the paucity of information about nosocomial infections in this setting, they performed monthly l-day on-site surveys of 12 North Carolina extended care facilities. Long-term care facilities include extended care facilities (which suggests association with an acute care facility) and nursing homes (which suggests a free-standing institution), although all three terms are often used interchangeably. Long-term care beds may be categorized as skilled care or intermediate care, the latter requiring less intensive nursing.

What do we know about infections that occur in longterm care facilities? The annual number of nosocomial infections in nursing homes is estimated to be 1.5 million by the Centers for Disease Control. ${ }^{3}$ Collecting accurate surveillance data is difficult. The best we can do at present is to apply hospital criteria to nursing homes, which is

From the Epidemiology Department, Clarkson Hospital, Department of Internal Medicine, University of Nebraska Medical Center, Omaha, Nebraska.

Address reprint requests to Philip W. Smith, MD, Epidemiology Department, Clarkson Hospital, Department of Internal Medicine, University of Nebraska Medical Center, Omaha, NE 68105. unsatisfactory in view of the less extensive medical record and the relative paucity of microbiologic and other laboratory data. Several prevalence surveys of (usually skilledcare) nursing homes have found nosocomial infection rates of $3 \%$ to $18 \%$, comparable in magnitude to the nosocomial infection rates in most acute care hospitals. ${ }^{4-8}$ The denominator is average resident census per month, rather than number of discharges.

Price et al found a prevalence rate of $5.4 \%$, which may be artifactually low due to reliance on physicians' notes and recall of infections during the prior month. They also departed from some of the other prevalence surveys and CDC criteria by not counting asymptomatic bacteriuria as a nosocomial infection. We do not know if cultures were performed in the course of surveillance. Unlike Garibaldi's survey, ${ }^{7}$ Price did not detect infection clustering suggesting infection outbreaks.

It should not be surprising that the problem of nursing home-acquired infection is so prevalent. We are dealing with a host whose immunity is impaired by the aging process as well as by multiple underlying medical problems, such as diabetes mellitus, malignancy, peripheral vascular disease, and chronic obstructive pulmonary disease. Impaired mentation predisposes to aspiration pneumonia and decubitus ulcers. Incontinence and urinary catheters lead to urinary tract infection. Nursing home residents generally receive multiple medications which adversely affect resistance to infection: steroids depress cell-mediated immunity, antibiotics disturb normal bacterial flora, and psychotropic drugs may decrease normal mucociliary clearance or urinary How.

The environmental reservoir is less important in nursing homes than in hospitals, but recent descriptions of tuberculosis, ${ }^{9}$ group A streptococcal disease ${ }^{10}$ and hemorrhagic $E$. coli diarrhea ${ }^{11}$ in nursing homes remind us of the presence of human and inanimate reservoirs of infection in this setting. In addition, a means of transmission is very much in evidence in long-term care facilities. Not only do staff go from room-to-room, as in hospitals, but 
nursing homes have to contend with the problem of mobile residents as possible vectors.

Most of the nursing homes surveyed by Price were applying some effort toward infection prevention. All 12 of the extended care facilities had a designated infection control practitioner (ICP). However, none of the ICPs had received specific infection control training, and most had multiple other responsibilities, such as director of nurses, staff development or employee health. The ICPs generally spent only 1 hour per week on infection control activities. All facilities had an employee health program and written patient care practices, although the approach to these control methods varied greatly. Surprisingly, 10 of the 12 facilities conducted regular surveillance for infections, although no standard criteria were established defining nosocomial infection. Community-acquired infections were included in the numerator with nosocomial infections, but we are not told what percent of the total they comprise. Considering the mean length of stay, this may not introduce significant error.

We cannot simply apply hospital infection control techniques to nursing homes; long-term care facilities have unique problems to face. The psychological toll of dealing with someone whose host resistance is declining has been amply discussed: there is no focus on recovery, no hightechnology glamour, no great economic reward. Other realities include high personnel turnover, a high percentage of nonprofessional staff, and the lack of good scientific studies in the field. On the positive side, there has been an exponential increase in geriatric infectious disease literature and research, including interest in the problems of the elderly in nursing homes.

Where can progress be made? Price's thorough survey underscores several directions to be pursued:

- Criteria for the diagnosis of nosocomial infections need to be developed specifically for nursing homes. Current hospital-oriented criteria depend heavily on the medical record and good microbiologic data.

- While pre-employment and annual screening for tuberculosis is fairly common, comprehensive employee health programs (which include immunization programs and work restrictions for sick employees) are rarely found, and would be relatively easy to implement.

- Residents should be screened for tuberculosis on admission and annually, and given influenza and pneumococcal vaccines. The Immunization Practices Advisory Committee recommends the pneumococcal vaccine for adults over $65^{12}$ and has named nursing home residents a target group for annual influenza vaccination. ${ }^{13}$ Nevertheless, vaccination rates in various surveys have been disappointing. In view of the severity of influenza and pneumococcal pneumonia in nursing home residents and the safety of the vaccines, residents should be vaccinated in spite of the fact that vaccine efficacy in the elderly is less than in the younger population.

- Most facilities have resident care practices and environmental policies and procedures, although they frequently contain out-of-date recommenda- tions. It would be reasonable for the Centers for Disease Control to develop guidelines for skilled and intermediate care facilities similar to the ones they develop for hospitals.

- Many extended care facilities have poor isolation facilities, notably positive pressure rooms with recirculated, inadequately filtered air and few sinks for handwashing. A rheostatically controlled window fan is the remedy for ventilation suggested by the authors, and architects should solve these problems prospectively in future nursing home designs.

Cost is a vital concern for infection control efforts in long-term care facilities; most of the above measures would be relatively inexpensive. Interestingly, Price found a number of instances in which current nursing home practices were not only substandard but more costly than recommended practices. Examples include annual chest $\mathrm{x}$-rays on employees, urinary catheter irrigations and routine administration of prophylactic antibiotics to catheterized patients.

There is a need for more research on nursing homeacquired infections, more study of host factors which can be modified, and more educational programs for nursing home personnel in the area of infection control. Noticeable progress is being made in the educational area. The Nebraska Infection Control Network is a cooperative effort involving the State Department of Health, state hospital and nursing home associations, and regional APIC Chapter. The Network sponsors local and regional seminars for nursing home infection control practitioners. Other states are also turning attention to similar programs.

As Pasteur said, "the microbes will have the last word." Yes, but only in due time. Surveys like the one by Price provide a good basis for directing future research, clinical and educational efforts on behalf of the elderly in longterm care facilities.

\section{REFERENCES}

1. Francese P: Presentation to the American College of Hospital Administrators San Francisco, April, 1985.

2. Price LE, Sarubbi FA, Rutala WA: Infection control programs in twelve North Carolina extended care facilities. Infect Control 1985; 6:437-441.

3. Haley RW, Culver DH, White JW, et al: The nationwide nosocomial infection rate-A need for vital statistics. Am J Epidemiol 1985; 121:159-167.

4. Lester MR: Looking inside 101 nursing homes. Am / Nurs 1964; 64:111-116.

5. Cohen ED, Hierholzer WJ, Schilling CR, et al: Nosocomial infections in skilled nurisng facilities: A preliminary survey. Public Heallh Rep 1979; 94:162-166.

6. Magnussen MH, Robb SS: Nosocomial infections in a long-term care facility. Am I Infect Control 1980; 8:12-17.

7. Garibaldi RA, Brodine S, Matsumiya S: Infections among patients in nursing homes-Policies, prevalence, and problems. N Engl J Med 1981; 305:731-735.

8. Setia U, Serventi I, Lonenz P: Nosocomial infections among patients in a longterm care facility: Spectrum, prevalence and risk factors. Am J Infect Control $1985 ; 13: 57-62$.

9. Stead WW, Lofgren JP, Warren E, et al: Tuberculosis as an epidemic and nosocomial infection among the elderly in nursing homes. $N$ Engl J Med 1985; 312:1483-1487.

10. Ruben FL, Norden CW, Heisler B, et al: An outbreak of Streptococcus pyogenes infections in a nursing home. Ann Intern Med 1984; 101:494-496.

11. Hemolytic-uremic syndrome associated with Escherichia coli 0157:H7 enteric infections-United States, 1984. MMWR 1985; 34:20-21.

12. Update-Pneumococcal polysaccharide vaccine usage. United States. $M M W R$ $1984 ; 33: 273-281$.

13. Prevention and control of influenza. MMWR 1985; 34:261-275. 